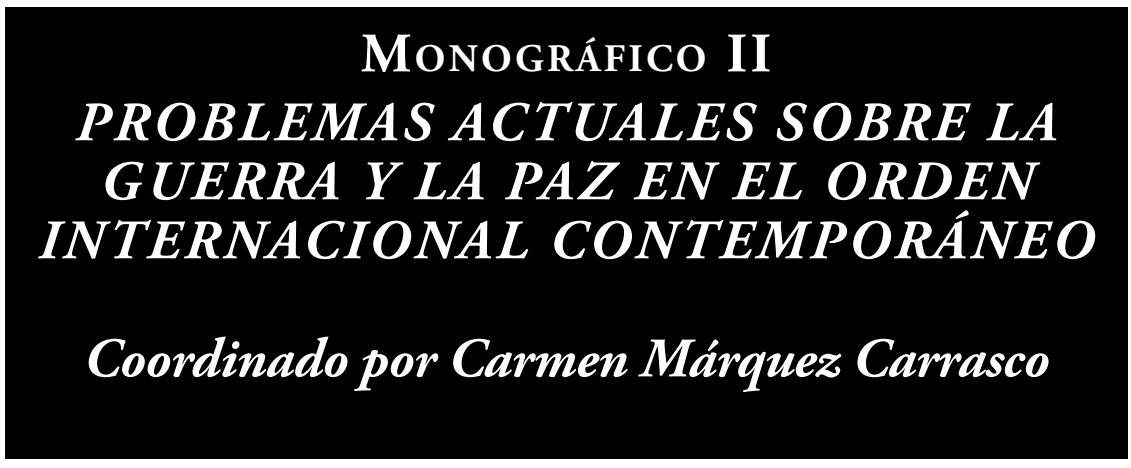




\title{
Problemas actuales sobre la guerra y la paz en el orden internacional contemporáneo
}

\section{Current Problems on War and Peace in the Contemporary International Order}

\author{
Carmen Márquez Carrasco ${ }^{1}$ \\ Universidad de Sevilla (España)
}

El presente número monográfico de la Revista Araucaria, que lleva por título Problemas actuales sobre la guerra y la paz en el orden internacional contemporáneo, incluye una serie de temas seleccionados por su relevancia para el debate científico en torno a la progresiva difusión de los límites entre los estatutos y nociones de guerra y paz en el orden internacional contemporáneo. En ellos se incluyen reflexiones sobre la transformación de la guerra, que ha permitido hablar en la actualidad de una cuarta generación o tipos de 'guerra', las "nuevas guerras", como las ha calificado la Profesora Mary Kaldor, o, como también se las ha llamado, las guerras sin Estado, e incluso se ha presentado nuevas formas de violencia (violencia urbana, violencia criminal) bajo el apelativo de "novísimas guerras", a las que se han referido en sus trabajos los Profesores Tatiana Moura y José Manuel Pureza, y su incidencia en el sistema internacional, en particular en lo que afecta a objetivos o fines que siguen siendo básicos, la paz y seguridad internacionales.

Este monográfico tiene carácter multidisciplinar pues incorpora diversidad de análisis y de sectores implicados de disciplinas científicas tales como la Ciencia Política y las Relaciones internacionales, y el Derecho Internacional.

Este monográfico es el resultado de un esfuerzo y trabajo colectivos, por lo que deseamos expresar nuestro sincero agradecimiento a todos los autores y autoras por haber respondido con enorme generosidad a la solicitud que se les hizo llegar y por haber contribuido con sus trabajos a esta publicación.

\footnotetext{
1 (cmarque@us.es) Catedrática de Derecho Internacional Público y Relaciones Internacionales de la Universidad de Sevilla. Este estudio ha sido realizado en el marco de la investigación del Work Package 10 (Human Rights Violations in Conflict-Settings) del Proyecto de Investigación FRAME (Fostering Human Rights Among Internal and External EU Policies), Séptimo Programa Marco de la Comisión Europea.
}

Araucaria. Revista Iberoamericana de Filosofía, Política y Humanidades, año 16, $\mathrm{n}^{\circ} 32$. Segundo semestre de 2014. Pp. 199-203. ISSN 1575-6823 e-ISSN 2340-2199 doi: 10.12795/araucaria.2014.i32.10 
Asimismo queremos agradecer al Profesor Hermosa Andújar la deferencia de haber pensado en mí como coordinadora de esta serie de trabajos.

Tras las reflexiones de carácter introductorio y a título de presentación que se realizan en estas primeras páginas, el estudio monográfico se articula en torno a nueve contribuciones de enorme actualidad e interés.

En el primer artículo, el Rector de la Universidad de la Paz, el Dr. Francisco Rojas Aravena, analiza la cooperación en seguridad y defensa en América Latina en el contexto de cambios globales que experimenta el sistema internacional. Tomando como referencia el año 2014 como fecha de conmemoración de los 100 años desde que se inició la I Guerra Mundial (la primera guerra "moderna"), el autor señala que los últimos acontecimientos en Europa indican que no se han aprendido las más importantes lecciones que esta guerra dejó, en particular en lo relativo al multilateralismo, la resolución de conflictos, al tratamiento al terrorismo y a las migraciones forzadas. Esta situación, indica el Dr. Rojas, se produce en un contexto de cambios globales que incide en la evolución del sistema internacional, en cuyo marco es reseñable la contribución que América Latina y el Caribe realizan en la actualidad de manera sustantiva a la paz y la estabilidad global.

El segundo artículo, elaborado por el Profesor Dr. Luis Ochoa Bilbao, de la Benemérita Universidad de Puebla (México), trata sobre la guerra y el uso de la fuerza desde la perspectiva de la Sociología Histórica de las Relaciones Internacionales. En su trabajo el autor el artículo analiza los cambios en el sistema internacional contemporáneo para detectar los elementos que persisten y que dan cuenta de la capacidad de los Estados nacionales por mantener bajo su control los medios para ejercer el uso de la fuerza de manera efectiva. El ensayo parte del debate contemporáneo de las relaciones internacionales en el que se propone que los Estados nacionales pierden en el siglo XXI su capacidad de mantener la vigencia del monopolio de la violencia legítima y de la guerra. Sin embargo, añade el autor, el uso de la fuerza en incursiones punitivas y disuasivas sigue siendo un elemento que manifiesta la continuidad del poder estatal en el sistema internacional.

En el tercer trabajo, la Profesora Dra. Ximena Fuentes Torrijo, de la Universidad Adolfo Ibáñez de Chile, examina el marco jurídico internacional sobre la prohibición del uso de la fuerza. La autora subraya que en el contexto del sistema de seguridad internacional que pretende instaurar la Carta de las Naciones Unidas el principio de prohibición del uso de la fuerza establecido en el artículo 2.4 es una piedra angular. Esta disposición está constantemente sometida a interpretaciones controvertidas que tratan de delimitar su contenido y alcance.

El cuarto artículo, realizado por el Dr. Ricardo Arredondo, de la Universidad de Buenos Aires, aborda la responsabilidad de proteger desde la perspectiva latinoamericana. El autor examina el principio de la responsabilidad 
de proteger, que plantea un dilema entre el respeto a los principios de soberanía y no intervención y la necesidad de proteger a las poblaciones en peligro en casos de violaciones graves, masivas y sistemáticas de sus derechos humanos y/o del Derecho internacional humanitario, y, en este contexto, analiza con profundidad las posturas de América Latina a este respecto.

La quinta contribución, por parte del Profesor Dr. Pablo Antonio Fernández Sánchez, de la Universidad de Sevilla, presenta una reflexión sobre la contribución de América Latina a la construcción teórica de las Operaciones de Mantenimiento de la Paz. El autor señala que la experiencia llevada a cabo en esta región durante los grandes conflictos que asolaron Centro América en los años 80 y 90 y la crisis permanente de algunos Estados, permitió una participación activa de la Organización de las Naciones Unidas que dio lugar a novedades en la puesta en práctica de las Operaciones de Paz, que como instrumento para mantener o restablecer la paz, fueron ensayadas en esta zona del mundo y exportadas luego a otras, tan comprobar sus éxitos.

El sexto artículo se debe a la Dra. Cristina Churruca Muguruza, Profesora de la Universidad de Deusto, quien analiza el reto de la seguridad humana en América Latina. Su trabajo aborda el fenómeno de la violencia en América Latina y sus consecuencias en términos de seguridad humana, mostrando un panorama de la violencia en la región más allá de las tasas conocidas de homicidios y señalando el impacto de la violencia en la vida de las personas en particular una dimensión menos conocida y muy poco estudiada todavía como es el desplazamiento forzado de población. Este problema en particular -añade- evidencia la falta de seguridad y desprotección de las personas y la existencia de territorios estratégicos controlados por el crimen organizado. La autora plantea que hasta que los Estados y las organizaciones internacionales no reconozcan el problema de la violencia en toda en su dimensión el crimen organizado seguirá impune.

El séptimo trabajo corresponde a la Dra. Fannie Lafontaine, Profesora de la Universidad de Laval (Canadá), en el que analiza algunos aspectos del contexto que marca el nacimiento de la jurisdicción penal internacional permanente - la Corte Penal Internacional - a saber, las expectativas que se colocaron en las instituciones de justicia penal internacional en los años 90 y posteriores, y el fracaso parcial de estas instituciones para mantenerse a la altura de esas previsiones poco realistas. La autora aborda algunos elementos de consideración para el futuro del sistema de justicia penal internacional y trata asimismo de algunos de los fundamentos sobre los que el sistema está construido, sirviendo de base para el argumento de que a pesar de un legado mixto y diversas deficiencias, no habrá marcha atrás hacia un vacío legal en el Derecho internacional en lo relativo a la rendición de cuentas por crímenes internacionales que se comenten tanto en tiempo 
de guerra como en tiempo de paz.

La octava contribución debe su autoría a la Dra. Magdalena Martín Martínez, de la Universidad de Málaga. Su trabajo sobre Iberoamérica y la Corte Penal Internacional (CPI) examina los logros y retos de lo que califica como interacción compleja e inacabada. La autora parte de la hipótesis centrada en las expectativas que en Iberoamérica despiertan las actividades a desarrollar por la CPI, lo que a corto y medio plazo parecen indicar que mientras que África ha sido el continente estrella en la primera década de vida de la CPI, Iberoamérica puede ocupar un papel relevante cuando la CPI alcance su mayoría de edad. Su artículo repasa primero la aportación iberoamericana a la CPI, desde la ratificación e implementación del Estatuto de Roma hasta la Conferencia de Revisión de Kampala de 2010, para a continuación abordar la otra dimensión de esta interacción recíproca, analizando cuales han sido las principales aportaciones que el Estatuto de Roma ha supuesto para la región, así como los retos y desafíos pendientes.

El noveno trabajo que compone este monográfico, sobre las mujeres y la guerrilla, ha sido realizado por la Dra. Claudia Jiménez Sánchez, de la Universidad de Málaga. La autora examina la naturaleza de la guerra de guerrillas desde una perspectiva de género y con una especial consideración de su impacto en los diversos escenarios iberoamericanos en los que se libró o se libran luchas armadas con la intervención de grupos guerrilleros. El trabajo toma en consideración la incorporación de las mujeres a la guerrilla y los papeles que éstas han desarrollado en este contexto. 